\title{
The Inhibition of Amyloid Fibrillation Using the Proteolytic Products of PQQ-Modified $\alpha$-Synuclein
}

\author{
Natsuki Kobayashi ${ }^{1}$, Jihoon $\mathrm{Kim}^{1}$, Kazunori Ikebukuro ${ }^{1}$ and Koji Sode ${ }^{1,2, *}$ \\ ${ }^{I}$ Department of Biotechnology, Graduate School of Engineering, Tokyo University of Agriculture \& Technology and \\ ${ }^{2}$ Department of Technology Risk Management, Graduate School of Technology Management, Tokyo University of Agri- \\ culture \& Technology, Japan
}

\begin{abstract}
The inhibition of amyloid fibril and/or oligomer formation allows a novel therapeutic approach to neurodegenerative diseases such as Parkinson's disease. We have previously reported that pyrroloquinoline quinone (PQQ), a cofactor in the bacterial oxidative metabolism of alcohols, prevents the amyloid formation of $\alpha$-synuclein, which is the causative factor of Parkinson's disease. Moreover, PQQ-modified $\alpha$-synuclein is also able to inhibit the fibrillation of intact $\alpha$ synuclein. Here, we demonstrate that PQQ-modified peptide fragments, the proteolytic products of PQQ-modified $\alpha$ synuclein, prevent the amyloid formation of full-length $\alpha$-synuclein, and that these inhibitory effects are derived from the PQQ modification of the peptide. Moreover, these effects are likely to be peptide-sequence-dependent. Thus, the specific interaction between the full-length $\alpha$-synuclein and the peptide region of the PQQ-modified peptide prevents amyloid formation.
\end{abstract}

Key Words: $\alpha$-Synuclein, amyloid fibril, inhibitor, Parkinson's disease, peptide, pyrroloquinoline quinone.

\section{INTRODUCTION}

Conformational diseases, represented by neurodegenerative diseases, are characterized by the formation and accumulation of misfolded proteins or amyloid fibrils. Considering that the formation of oligomers and/or amyloid fibrils plays a crucial role in the toxicity of the proteins and the onset of consequent neurodegenerative diseases, the inhibition of their formation allows a novel therapeutic approach [1-4].

Several small compounds have been reported to prevent the fibril formation of amyloid-forming proteins [5-11]. Some of these compounds have a quinone structure, and covalently bind to the Lys residues of the amyloid-forming protein via Schiff-base formation [8-11].

We have also demonstrated that pyrroloquinoline quinone (PQQ) (Fig. 1A), which is a cofactor in the bacterial oxidative metabolism of alcohols, prevents the amyloid formation of $\alpha$-synuclein ( $\alpha$-Syn), which plays a crucial role in the onset of Parkinson's disease [12]. We have concluded that PQQ inhibits $\alpha$-Syn fibrillation by binding with $\alpha$-Syn covalently via Schiff-base formation (Fig. 1B). Moreover, PQQ-modified $\alpha$-Syn is also able to prevent $\alpha$-Syn fibril formation [12].

This inhibitory effect of PQQ-modified $\alpha$-Syn is considered to be due to the intermolecular interaction between PQQ-modified $\alpha$-Syn and intact $\alpha$-Syn. However, it is still unclear whether or not PQQ-modified full-length $\alpha$-Syn must interact with intact $\alpha$-Syn to inhibit the consequent fibrilla-

*Address correspondence to this author at the 2-24-16 Naka-cho, 184-8588 Tokyo, Koganei, Japan; Tel/Fax: +81-42-388-7027;

E-mail: sode@cc.tuat.ac.jp tion. For therapeutic applications, a PQQ-modified peptide with a smaller molecular weight is likely to be more appropriate than the PQQ-modified full-length protein, which has a higher molecular weight (molecular weight of full-length $\alpha$-Syn, $14400 \mathrm{Da}$ ).

In this paper, we investigate the effects of proteolytic $\alpha$ Syn and PQQ-modified $\alpha$-Syn on full-length $\alpha$-Syn amyloid formation. We demonstrate that proteolytic products of PQQ-modified $\alpha$-Syn inhibit the amyloid formation of fulllength $\alpha$-Syn. Our current results suggest that inhibitory effects of PQQ-modified peptides are likely due to the PQQ modification of specific sequences, as not all proteolytic product of PQQ-modified $\alpha$-Syn showed the inhibition.

\section{METHODS}

\section{Chemicals}

Pyrroloquinoline quinone (PQQ) was kindly donated by Mitsubishi Gas Chemical Company, Inc.

\section{Preparation of Recombinant $\alpha-S y n u c l e i n$}

Human wild-type $\alpha$-Syn was expressed in the $E$. coli BL21 (DE3) cell line transfected with the pET28a $(+) / \alpha-S y n$ plasmid and purified, as we reported previously [12].

\section{PQQ Modification of $\alpha$-Synuclein}

PQQ-modified $\alpha$-Syn was prepared as we reported previously [12]. $\alpha$-Syn $(140 \mu \mathrm{M})$ and PQQ $(1.4 \mathrm{mM})$ were coincubated in PBS buffer $\left(8.1 \mathrm{mM} \mathrm{Na} \mathrm{HPO}_{4}, 1.4 \mathrm{mM}\right.$ $\mathrm{KH}_{2} \mathrm{PO}_{4}, 137 \mathrm{mM} \mathrm{NaCl}, 2.7 \mathrm{mM} \mathrm{KCl}, \mathrm{pH} 7.3$ ) at $37^{\circ} \mathrm{C}$ with shaking for over $100 \mathrm{~h}$. Then, the incubated sample was loaded onto a PD-10 column (GE Healthcare Bio-science 
Corp.) to remove the intact PQQ. The eluted fractions containing adduct without intact PQQ were collected as PQQmodified $\alpha$-Syn ( $\alpha$-Syn-PQQ).

\section{Proteolytic Digestion of $\alpha-S y n u c l e i n$ and PQQ-Modified $\alpha-S y n u c l e i n$}

Limited proteolysis of $\alpha$-Syn and $\alpha$-Syn-PQQ with endoproteinase Glu-C was performed at $37^{\circ} \mathrm{C}$ for $18 \mathrm{~h}$ according to the manual described in the product information for GluC. The reaction was conducted at a mixture ratio of $3 / 100$ (w/w) in PBS buffer, and the protein concentrations of $\alpha$-Syn and $\alpha$-Syn-PQQ were kept at $4 \mathrm{mg} / \mathrm{ml}$. Under these conditions, Glu-C digests the carboxyl side of both the Asp and the Glu residues specifically (Fig. 1C). After proteolytic digestion, the undigested $\alpha-S y n / \alpha-S y n-P Q Q$ and Glu-C were removed from the proteolytic mixtures by ultrafiltration through Amicon Ultra-4 filters (MWCO, 5000 Da; Millipore). The resulting ultrafiltrate containing digested $\alpha-\operatorname{Syn} / \alpha-$ Syn-PQQ was further separated by reverse-phase chromatography (RPC). The ultrafiltrate was then loaded onto a Resource RPC column (column volume, $1 \mathrm{ml}$; GE Healthcare
Bio-science Corp.) and eluted with a 2-80\% acetonitrile gradient in buffer containing $0.05 \%$ trifluoroacetic acid (TFA). The eluate was monitored by the absorbance at $210 \mathrm{~nm}$ $\left(\mathrm{Abs}_{210}\right)$ and $280 \mathrm{~nm}\left(\mathrm{Abs}_{280}\right)$ simultaneously. Each 1-ml eluted fraction was collected and stored at $-80^{\circ} \mathrm{C}$ after lyophilization. The proteolytic $\alpha$-Syn fractions were designated as $\mathrm{S}-1, \mathrm{~S}-2, \mathrm{~S}-3$, and so on, in the order of elution, and those of $\alpha$-Syn-PQQ were correspondingly designated as SP-1, SP2 , SP-3, and so on.

\section{Amyloid Fibril Formation Analysis}

Purified $\alpha$-Syn was ultracentrifuged $\left(150000 \mathrm{~g}, 1 \mathrm{~h}, 4^{\circ} \mathrm{C}\right)$ to remove any aggregates. The lyophilized proteolytic products of $\alpha$-Syn and $\alpha$-Syn-PQQ were dissolved in PBS buffer. Each dissolved proteolytic product was mixed with 1.0 $\mathrm{mg} / \mathrm{ml}(70 \mu \mathrm{M}) \alpha$-Syn. The concentration of each proteolytic product in the mixed solution was 3-fold higher than that of the eluate. A control solution containing $1.0 \mathrm{mg} / \mathrm{ml}(70 \mu \mathrm{M})$ of $\alpha$-Syn alone was also prepared. All samples contained $0.02 \% \mathrm{NaN}_{3}$ as an antiseptic agent. For each sample, $200 \mu \mathrm{l}$ were aliquoted in triplicate into a 96-well microtiter plate

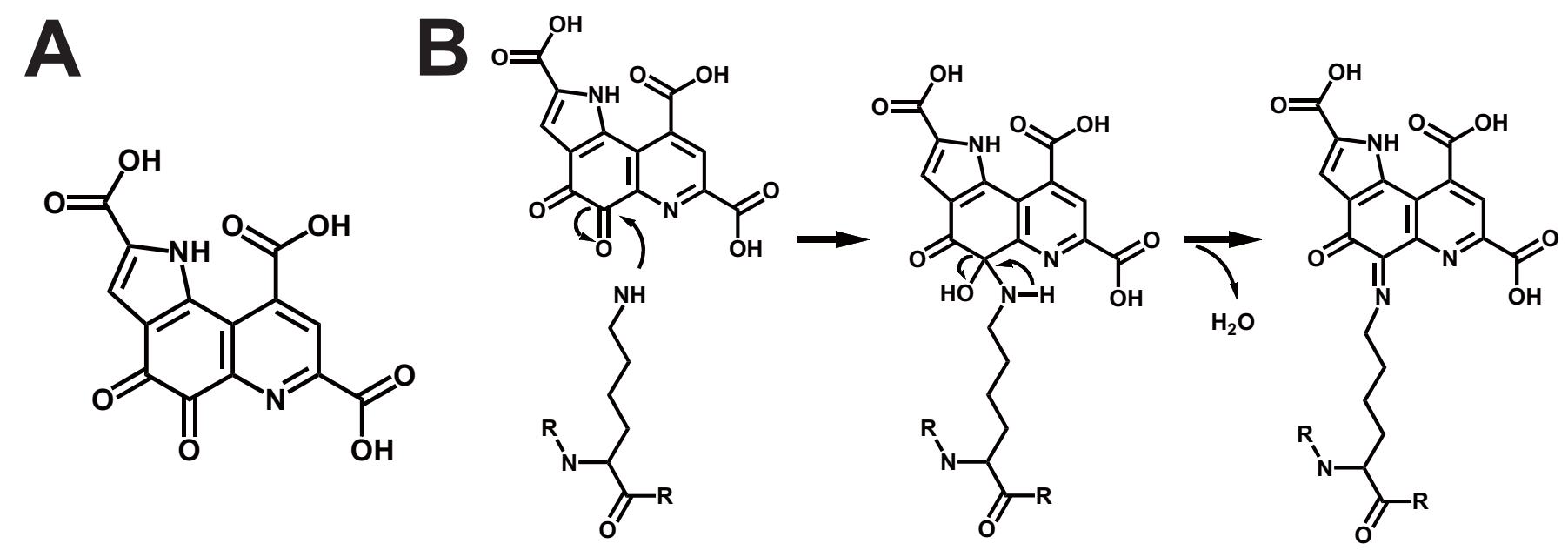

C

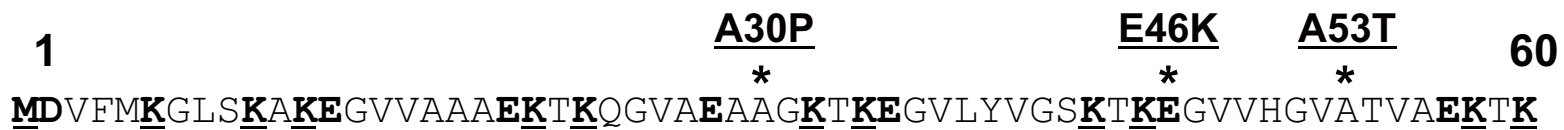

61

95

EQVTNVGGAVVTGVTAVAQㅍVEGAGSIAAATGFV

96

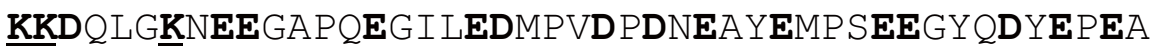

Fig. (1). Structure of pyrroloquinoline quinone (PQQ) (A), scheme of its Schiff-base formation with Lys residues of the peptides (B) and primary structure of $\boldsymbol{\alpha}$-synuclein (C). (A) Chemical structure of PQQ. (B) "R" indicates the amino-acid residue next to the Lys residue. (C) The primary structure of $\alpha$-synuclein can be divided into three characteristic regions: the N-terminal region (1-60; top), the NAC region (61-95; middle) and the C-terminal region (96-140; bottom). The positions of three missense mutations (Ala53Thr, Ala30Pro and Glu46Lys) that are related to the early onset of Parkinson's disease are marked with asterisks (*). PQQ binds to the Lys (K) residues and amino group of the first Met (M) residue (bold and underlined) via Schiff-base formation. Endoproteinase Glu-C specifically digests the carboxyl side of the Asp (D) and the Glu (E) residues (bold). 
together with a Teflon ball. The plates were covered with a seal and incubated at $37^{\circ} \mathrm{C}$ with shaking at approximately $700 \mathrm{rpm}$. Each sample was run in 3-5 replicates. Amyloid formation was monitored by thioflavin $\mathrm{T}$ (TfT) fluorescence. Aliquots of $2.5 \mu \mathrm{l}$ were removed from the incubated sample and added to $250 \mu \mathrm{l}$ of $25 \mu \mathrm{M}$ TfT in PBS buffer. TfT fluorescence was recorded at $486 \mathrm{~nm}$ with excitation at $450 \mathrm{~nm}$ using an ARVO MX 1420 multilabel counter (PerkinElmer). The lag-time values were calculated by the sigmoidal curve fitting of the measured data using GraphPad Prism 4.00 (GraphPad Software, Inc.). In the TfT solution, the compounds examined in this study were diluted down to $1 / 100$ of the concentration in the measurement mixture, which is enough to avoid the quenching effect of PQQ on the TfT analysis.

\section{RESULTS AND DISCUSSION}

\section{Isolation of the Proteolytic Products of $\alpha$-Synuclein and PQQ-Modified $\alpha$-Synuclein}

After Glu-C digestion, the proteolytic $\alpha$-Syn and $\alpha$-SynPQQ were separated by means of reverse-phase chromatography (RPC). The eluate was monitored by the absorbance at $210 \mathrm{~nm}\left(\mathrm{Abs}_{210}\right)$ and $280 \mathrm{~nm}\left(\mathrm{Abs}_{280}\right)$ simultaneously.

Figs. (2A and $\mathbf{2 B}$ top) show the chromatograms for Glu$\mathrm{C}$-digested $\alpha$-Syn and $\alpha$-Syn-PQQ detected at $\mathrm{Abs}_{210}$, respectively. Almost similar chromatograms were observed in these analyses, although there were differences in peak intensity. Three major peaks at a retention time of 5-8 min (Fig. 2, top, peaks (i), (iii) and (iv)), and four minor peaks at a retention time of 8-13 min were observed in both chromatograms (Figs. 2A and 2B, top).

On the other hand, the chromatograms monitored at $\mathrm{Abs}_{280}$ showed significant differences (Figs. 2A and 2B, middle). The chromatogram for Glu-C-digested $\alpha$-Syn monitored at $\mathrm{Abs}_{280}$ showed only major peaks at a retention time of 6-8 min (Fig. 2A, middle, peaks (iii) and (iv)). Since aromatic amino acids have absorption at $280 \mathrm{~nm}$, these peaks were probably derived from peptides containing aromatic residues such as Tyr, Phe and Pro ( $\alpha$-Syn has no Trp residue). However, the chromatogram for Glu-C-digested $\alpha$-SynPQQ showed a different pattern (Fig. 2B, middle). Two major peaks (Fig. 2B, middle, peaks (ii) and (iv)) and two minor peaks (Fig. 2B, middle, peaks (i) and (iii)) were observed at a retention time of 5-8 min. The latter two peaks (Fig. 2B, middle, peaks (iii) and (iv)) were also observed in the chromatogram for Glu-C-digested $\alpha$-Syn (Fig. 2A, middle, peaks (iii) and (iv)). However, the earlier two peaks (Fig. 2B, middle, peaks (i) and (ii)) were observed only in the chromatogram for Glu-C-digested $\alpha$-Syn-PQQ (Fig. 2A, middle). Furthermore, several additional broad peaks at a retention time of 13-15 $\mathrm{min}$ and 20-23 min were also observed, but only in the chromatogram for Glu-C-digested $\alpha$-Syn-PQQ (Fig. 2B, middle). In our previous study, PQQ-modified $\alpha$ Syn was revealed to show characteristic adsorption in the vicinity of $280 \mathrm{~nm}$, which was not observed in the intact $\alpha$ Syn [12]. This adsorption is due to the chromogenic property of PQQ. Therefore, the observed peaks showing adsorption in the vicinity of $280 \mathrm{~nm}$ represent the PQQ-modified partial peptides caused by the Glu-C digestion of $\alpha$-Syn-PQQ.
In order to investigate the inhibitory effect of PQQmodified $\alpha$-Syn partial sequences derived from Glu-C digestion on the amyloid formation of $\alpha-S y n$, we recovered fractions from Glu-C-digested $\alpha$-Syn-PQQ which showed adsorption in the vicinity of $280 \mathrm{~nm}$, at a retention time of 5-15 and 20-23 $\mathrm{min}$ (SP represents the fraction from Glu-C digested $\alpha$-Syn-PQQ; hereinafter, SP-6 to SP-15 and SP-21 to SP-23), and subjected them to further investigation. As controls, the fractions from Glu-C-digested $\alpha$-Syn eluted for the same retention period as the above-mentioned Glu-Cdigested $\alpha$-Syn-PQQ fractions ( $S$ represents the fraction from Glu-C digested intact $\alpha$-Syn; hereinafter, S-6 to S-15 and S21 to $\mathrm{S}-23$ ), were subjected to the same investigation.

\section{The Inhibitory Effect of the Proteolytic Products of PQQ-Modified $\alpha$-Syn Partial Sequences on the Amyloid Formation of $\alpha-S y n$}

The amyloid-fibril formation of full-length $\alpha$-Syn was investigated in the presence or absence of Glu-C-digested $\alpha$ Syn-PQQ fractions or Glu-C-digested $\alpha$-Syn fractions. The amyloid-fibril formation in each investigation was monitored by the increase in the TfT fluorescence intensity at $486 \mathrm{~nm}$ with excitation at $450 \mathrm{~nm}$. The results of the TfT analysis are shown in Figs. ( 2 bottom and $\mathbf{3}$ ). Fig. ( 2 bottom) summarizes the TfT fluorescence intensity after $84 \mathrm{~h}$ of incubation for each sample, showing the quantity of amyloid fibrils formed relative to the sample in which full-length $\alpha$-Syn was incubated without any proteolytic product. Amyloid firbril formation is considered to be nucleation-dependent, which is composed of nucleation, extension and equilibrium phases [13-15]. The final amount of amyloid fibril at certain incubation time represents fibrillation tendency including these three steps.

Among the samples tested (SP-6 to SP15 and SP-21 to SP-23), Glu-C-digested $\alpha$-Syn-PQQ showing adsorption in the vicinity of $280 \mathrm{~nm}$, SP-6, SP-7, SP-15 and SP-22, showed a marked inhibitory effect on the amyloid formation of full-length $\alpha$-Syn, compared with the amyloid formation in the absence of any proteolytic products (Fig. 2B, bottom). The amyloid formation of these samples were $44.1 \%$ (SP-6), $22.6 \%$ (SP-7), 26.8\% (SP-15) and 27.6\% (SP-22) of the amyloid formation observed in the absence of these fractions. However, most of the controls containing Glu-Cdigested $\alpha$-Syn fractions (S-6 to S-15 and S-21 to S-23) showed similar amounts of amyloid formation as the samples without proteolytic products (Fig. 2A, bottom). S-15 showed an inhibitory effect, and amyloid formation was only $40 \%$ compared with the samples without the fraction, although the impact was lower than that of the corresponding Glu-Cdigested $\alpha$-Syn-PQQ fraction, SP-15 $(26.8 \%)$. These results indicate that some of the proteolytic products of $\alpha$-Syn-PQQ have the potential to inhibit the amyloid-fibril formation of full-length $\alpha$-Syn.

For further consideration, we compared the time courses of amyloid formation monitored by the TfT fluorescence of the samples containing the Glu-C-digested $\alpha$-Syn-PQQ fractions SP-7, SP-15 and SP-22, which showed significant inhibitory effects, and the corresponding Glu-C-digested $\alpha$-Syn fractions S-7, S-15 and S-22 (Fig. 3). The incubation of $\alpha$ Syn in the absence of proteolytic products showed a gradual 
A
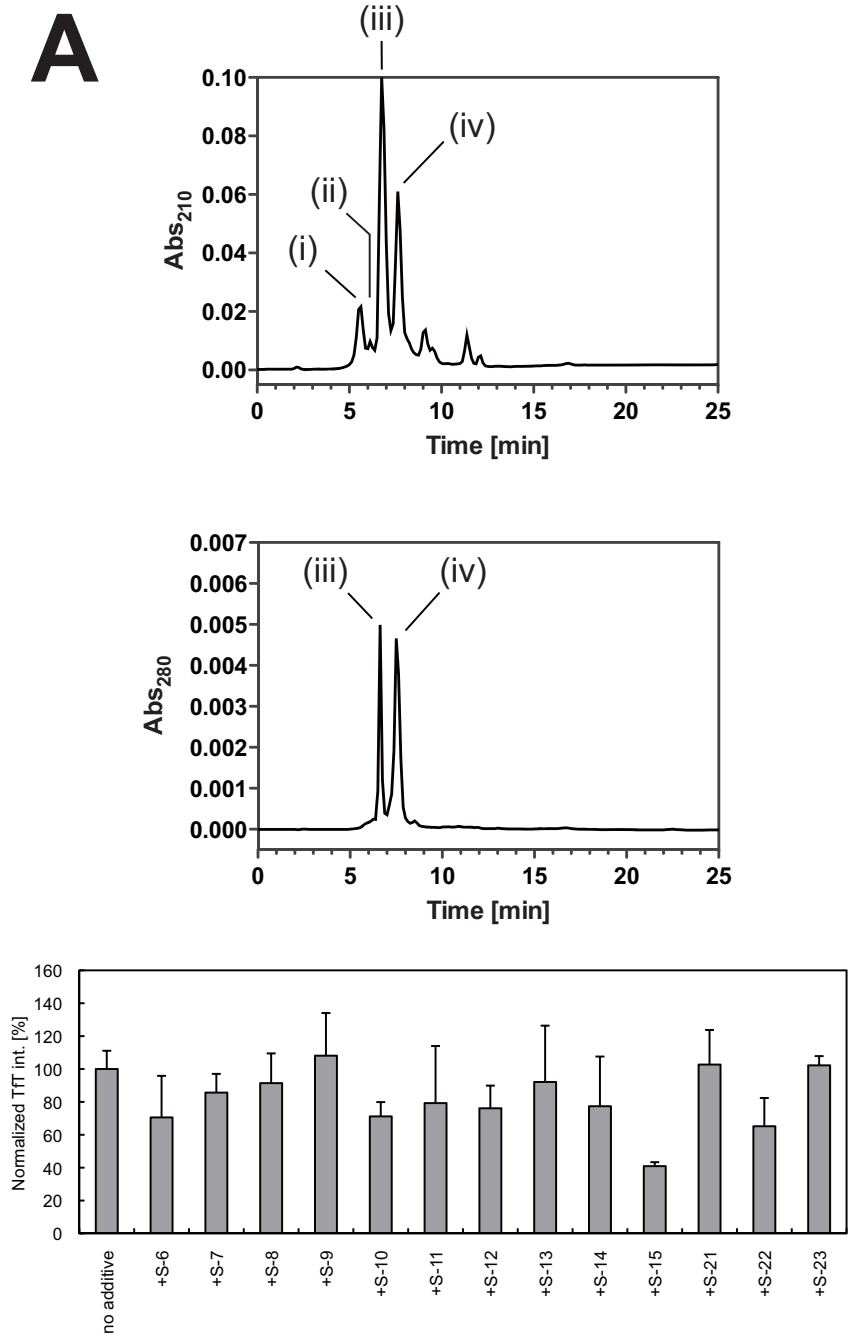

B

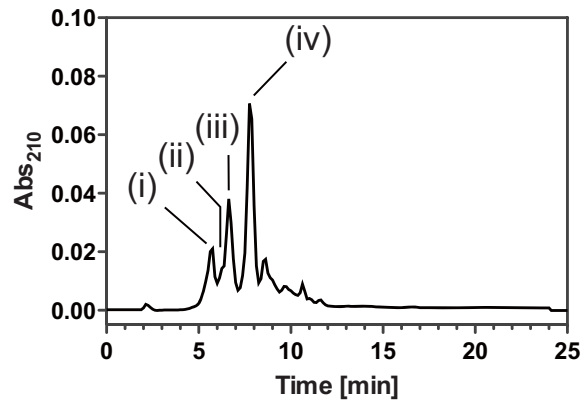

(iv)
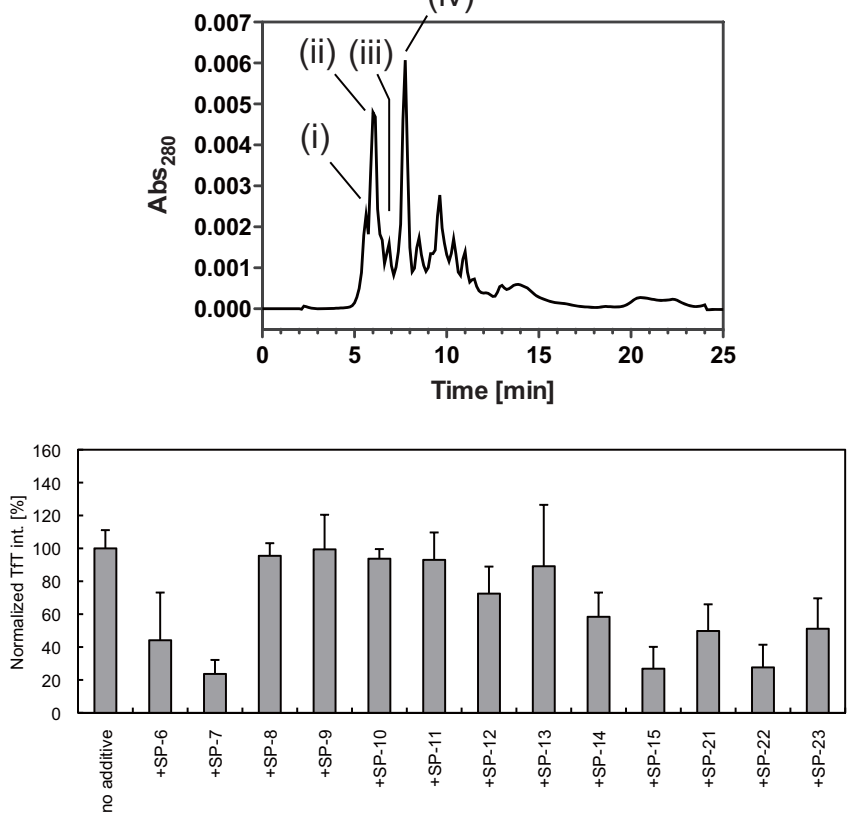

Fig. (2). Results of reverse-phase chromatography (RPC) separation of the proteolytic products of $\alpha$-synuclein ( $\alpha$-Syn) and PQQmodifeid $\alpha$-synuclein $(\alpha$-Syn-PQQ) and their effects on the amyloid fibril formation of full-length $\alpha$-Syn. Glu-C-digested $\alpha$-Syn $(\mathbf{A})$ and $\alpha$-Syn-PQQ (B) were separated by means of RPC. The eluate was detected at $\mathrm{Abs}_{210}$ (top) and $\mathrm{Abs}_{280}$ (middle) simultaneously. Roman numbers ((i) to (iv)) represent peaks at a retention time of 5-8 min and each number correspond to each peak observed at same retention time. After lyophilization, the effects of each fractionated Glu-C-digested $\alpha$-Syn (A, bottom) and $\alpha$-Syn-PQQ (B, bottom) on full-length $\alpha$-Syn amyloid formation were investigated. The vertical and horizontal axes indicate the relative final TfT intensity and the added fraction, respectively. The results are expressed as percentages of the value of $\alpha$-Syn alone ("no additive"), which is set at $100 \% n=3$.

increase along a typical sigmoidal curve, with a lag time of $46.3 \mathrm{~h}$ (Fig. 3, "No additive"), which is consistent with the typical amyloid-fibril formation kinetics as reported previously. S-7 did not show any significant inhibitory effect on full-length $\alpha$-Syn fibrillation, although a prolonged lag time in the increasing TfT fluorescence was observed. In contrast, SP-7 showed a marked decrease in TfT fluorescence (Fig. 3A). As shown in Figs. (2A and 2B bottom), both SP-15 and S-15 showed a marked decrease in amyloid formation. However, the time courses of amyloid formation in these samples were different. SP-15 showed a decrease in amyloid formation and lag time is almost same as control, whereas S-15 showed a reduced lag time with decreased amyloid formation (lag time of the control, $46.3 \mathrm{~h} ; \mathrm{S}-15,4.1 \mathrm{~h}$; SP-15, 45.7 h) (Fig. 3B). As described above, amyloid fibrillation is considered to be nucleation-dependent, which is composed of three steps; nucleation, elongation and equilibrium phase. Lag time represents the tendency of fibril nucleus formation, which is first step of amyloid fibrillation [13-15]. These results indicate that S-15 facilitates nucleation step of fulllength $\alpha$-Syn, while SP-15 dose not. SP-22 showed decreased amyloid formation, and S-22 also showed decreased amyloid formation, but the impact was smaller than in SP-22 for a similar time course (Fig. 3C).

Assuming that the fractions with corresponding numbers (corresponding proteolytic products) contain corresponding regions of the peptide fragments, these results indicate that the inhibitory effect of the PQQ-modified peptide fragments is due to the PQQ modification of the peptide fragments (Fig. 3). As not all PQQ-modified peptides inhibit full-length $\alpha$-Syn fibrillation (Fig. 2, bottom), this inhibitory effect is likely to be peptide-sequence-dependent. 
Our results suggest that PQQ-modified peptide fragments recognize and interact with the full-length protein and consequently inhibit fibrillation. Therefore, the peptide domain of the PQQ-modified peptide would recognize and interact with the full-length $\alpha$-Syn protein. Indeed, several peptide inhibitors have been reported and are expected to recognize target proteins specifically [16]. Moreover, the non-specific interaction of PQQ would also be avoided. Due to its high reactivity, $\mathrm{PQQ}$ is likely to react easily with the amino group
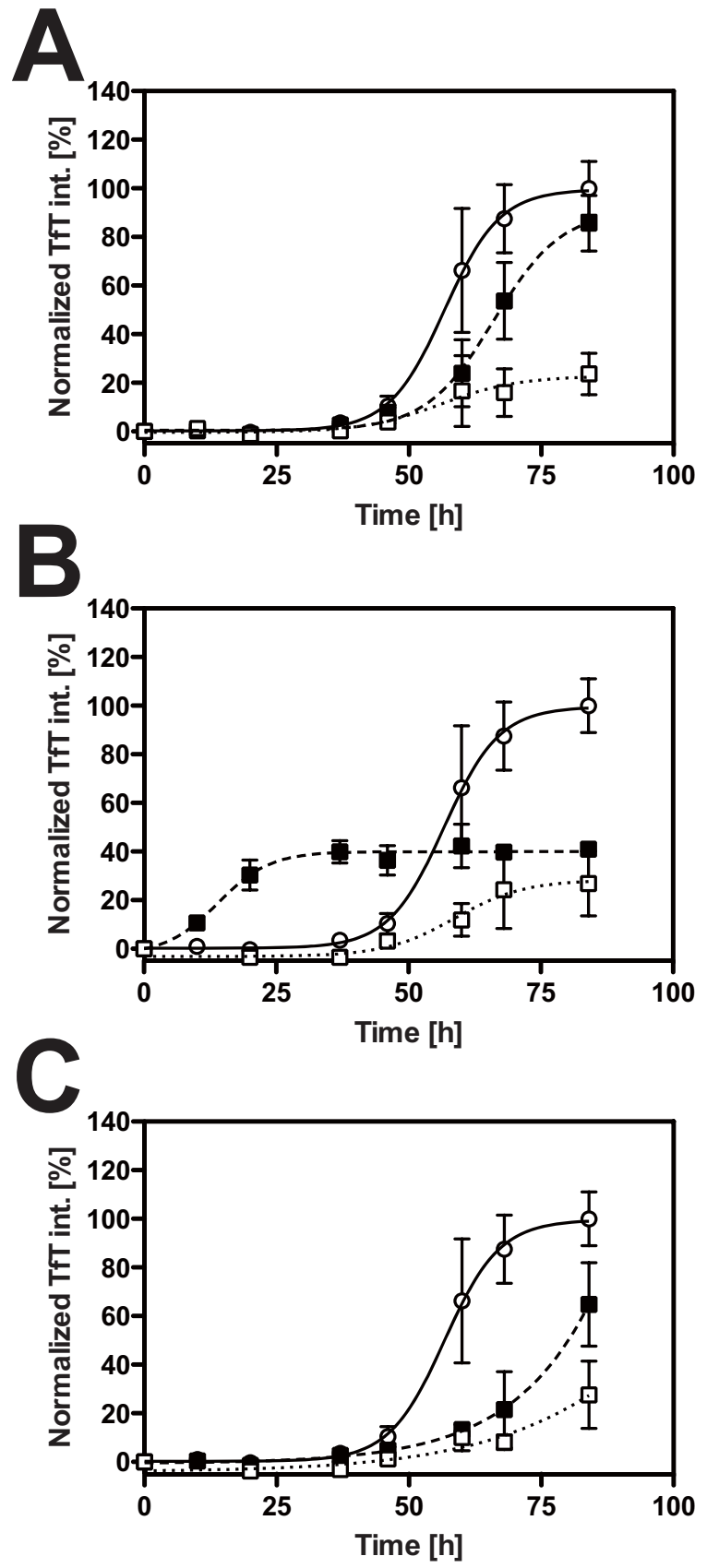

Fig. (3). Comparison of the effects of the fractions of proteolytic $\alpha$-synuclein ( $\alpha$-Syn) and PQQ-modified $\alpha$-synuclein ( $\alpha$-SynPQQ) with corresponding numbers on full-length $\alpha$-synuclein amyloid formation. The time course of $\alpha$-synuclein fibrillation and its mixtures with fractions 7 (A), 15 (B) and 22 (C). The final TfT intensity of the control sample, which contains $\alpha$-synuclein alone, is set at $100 \%$ : no additive (white circles), + proteolytic $\alpha$-Syn (black squares), + proteolytic $\alpha$-Syn-PQQ (white squares) $n=3$. of proteins or amino acids, consequently binding via Schiffbase formation. Forming an adduct with the peptide, the quinone domain of PQQ is blocked by Schiff-base formation (Fig. 1B), and thus any undesirable non-specific interactions would be avoided. Therefore, the PQQ modification of the peptide would confer specificity to PQQ.

The strategy of modifying a partial peptide fragment with a small compound to confer specificity to a small-molecule inhibitor can be applied to other amyloid-forming proteins utilizing the corresponding partial peptide fragments. Furthermore, it is also applicable to other small molecules that inhibit fibrillation by binding to the amyloid-forming protein covalently (such as dopamine, L-dopa, baicalein or rifampicin) [8-11]. Thus, this current strategy can confer specificity to inhibitors against various kinds of amyloid-forming proteins.

Although peptide-sequence identification is needed for further applications, this current basic strategy can be used to construct target-specific amyloid inhibitors, which may lead to the development of novel therapeutic approaches to conformational diseases.

\section{ACKNOWLEDGEMENTS}

The authors thank Dr. Stefano Ferri for kindly revising the manuscript. This work was supported by a Grant-in-Aid for Scientific Research (B) from the Ministry of Education, Culture, Sports, Science and Technology (MEXT) of Japan.

\section{REFERENCES}

[1] Tofaris GK, Spillantini MG. Alpha-synuclein dysfunction in Lewy body diseases. Mov Disord 2005; 20: (Suppl) S37-44.

[2] Goedert M, Spillantini MG. A century of Alzheimer's disease Science 2006; 314(5800): 777-81.

[3] Eriksen JL, Dawson TM, Dickson DW, Petrucelli L. Caught in the act: alpha-synuclein is the culprit in Parkinson's disease. Neuron 2003; 40(3): 453-6.

[4] Lansbury PT, Lashuel HA. A century-old debate on protein aggregation and neurodegeneration enters the clinic. Nature 2006; 443(7113): 774-9.

[5] Ono K, Yamada M. Vitamin A potently destabilizes preformed alpha-synuclein fibrils in vitro: implications for Lewy body diseases. Neurobiol Dis 2007; 25(2): 446-54.

[6] Ono K, Yamada M. Antioxidant compounds have potent antifibrillogenic and fibril-destabilizing effects for alpha-synuclein fibrils in vitro. J Neurochem 2006; 97(1): 105-15.

[7] Masuda M, Suzuki N, Taniguchi S, et al. Small molecule inhibitors of alpha-synuclein filament assembly. Biochemistry 2006; 45(19): 6085-94.

[8] Li J, Zhu M, Manning-Bog AB, Di Monte DA, Fink AL. Dopamine and L-dopa disaggregate amyloid fibrils: implications for Parkinson's and Alzheimer's disease. FASEB J 2004; 18(9): 962-4.

[9] Li J, Zhu M, Rajamani S, Uversky VN, Fink AL. Rifampicin inhibits alpha-synuclein fibrillation and disaggregates fibrils. Chem Biol 2004; 11(11): 1513-21.

[10] Conway KA, Rochet JC, Bieganski RM, Lansbury PT, Jr. Kinetic stabilization of the alpha-synuclein protofibril by a dopaminealpha-synuclein adduct. Science 2001; 294(5545): 1346-9.

[11] Zhu M, Rajamani S, Kaylor J, Han S, Zhou F, Fink AL. The flavonoid baicalein inhibits fibrillation of alpha-synuclein and disaggregates existing fibrils. J Biol Chem 2004; 279(26): 2684657.

[12] Kobayashi M, Kim J, Kobayashi N, et al. Pyrroloquinoline quinone (PQQ) prevents fibril formation of alpha-synuclein. Biochem Biophys Res Commun 2006; 349(3): 1139-44.

[13] Rochet JC, Lansbury PT, Jr. Amyloid fibrillogenesis: themes and variations. Curr Opin Struct Biol 2000; 10(1): 60-8. 
[14] Naiki H, Nakakuki K. First-order kinetic model of Alzheimer's beta-amyloid fibril extension in vitro. Lab Invest 1996; 74(2): 37483.

[15] Harper JD, Lansbury PT, Jr. Models of amyloid seeding in Alzheimer's disease and scrapie: mechanistic truths and physio- logical consequences of the time-dependent solubility of amyloid proteins. Annu Rev Biochem 1997; 66: 385-407.

[16] Estrada LD, Soto C. Inhibition of protein misfolding and aggregation by small rationally-designed peptides. Curr Pharm Des 2006; 12(20): 2557-67.

(C) Kobayashi et al.; Licensee Bentham Open.

This is an open access article licensed under the terms of the Creative Commons Attribution Non-Commercial License (http://creativecommons.org/licenses/ by-nc/3.0/) which permits unrestricted, non-commercial use, distribution and reproduction in any medium, provided the work is properly cited. 